En el mapa de Biutiful, el territorio y su topografía son fundamentales, así como el sitio que ocupa cada fragmento de ciudad y sus distancias. Hay un énfasis puesto en demostrar la lejanía. Desde las tomas interiores donde la ciudad por la ventana se muestra lejana y desenfocada, hasta las exteriores que enfatizan las fugas y la velocidad, Barcelona parece ser una ciudad fugaz. Las escenas de corridas, de autopista, de metro, de bus, de tren, y las largas caminatas, implican una duración de trayecto, una velocidad y una distancia. La ciudad representada es de escala metropolitana.

Esta ciudad difiere de la construida por Almodóvar que la muestra accesible, de locaciones cercanas entre sí, fácil de recorrer a pie, como si se tratase de un gran barrio. Un barrio colorido, con sus interiores y sus fachadas adornadas con esgrafiados y trencadís.

Por su parte Cesc Gay se da el gusto de hacer dos versiones de la misma ciudad. Dos Barcelonas corales y anónimas. La primera tiene tantos islotes cercanos que entre ellos se interrelacionan entre idas y vueltas. A lo largo de un día cada personaje vincula varios islotes con su itinerario. Pero en la versión del 2012, el mecanismo se minimiza y las voces del coro urbano hacen "duetos", dejando para el cierre el canto colectivo. Estas dos maneras de componer el guión trazan dos mapas distintos. En nueve años, la ciudad de Gay se aglutinó en puntos focales donde la historia del personaje comienza y termina, como una partícula urbana. Tal vez esta ciudad-individuo encapsulada en sus localizaciones sea la más contemporánea de las versiones.

El espacio se construye más allá de sus limitaciones físicas, pues se habita también en espacios imaginario y virtuales, y el sentido que se le da como soporte físico estará influenciado por dichas construcciones mentales que se proyectan sobre él, transformándolo en tanto sea ocupado. Y es allí realmente donde y cuando se habita. Muchas Barcelonas más caben dentro de esta ciudad que no termina ni en el mar ni en las montañas, tampoco en el río Besós o en el Llobregat, sino que se expande y multiplica dentro de los cuerpos atentos a dotar de sentido el espacio construido, y a hacer con é una nueva ficción de la ciudad. 1 Walter Benjamin describía el flâneur como la figura esencial
del moderno espectador urbano, un detective aficionado y un

BIBLIOGRAFÍA

ALMODÓVAR, P. Todo sobre mi madre. Guión Original. Madrid: El deseo ediciones.

BENJAMIN, W. (1972). El Paris del segundo imperio en Baudel
Taurus.

BURCH, N. (2008). La Praxis del cine. Madrid: Fndamentos.

CARERI, F. (2014) Walkscapes. El andar como práctica

estética. (2016). Pasear, detenerse. Barcelona: Gustavo Gill.

DELEUZE, G. (1984). La imagen-movimiento. Estudios sobre

DELGADO, M. (2002). Disoluciones urbanas. Medellín:

Universidad de Antioquia

GARCÍA ROIG, Manuel y MARTí ARÍS, Carlos. (2008). Hitchcock, Ford y Ozu (pág. 51). Barcelona: Fundación Caja de Arquitectos.

GAY, C. (2005). En la ciudad. Guión cinematográfico. En T. PALLASMAA, J. (2013). La imagen corpórea. Imaginación e
imaginario en arquitectura. Barcelona: Gustavo Gili. WENDERS, W. (2005). La verdad de las imágenes. En El acto

VILA, S. (1997). En La escenografía. Cine y arquitectura (pág. 148). Madrid: Cátedra.

ABSTRACT

Las películas que utilizan las ciudades como escenografía, sus calles, sus casas y su gente, montan una ciudad a partir de esas imágenes-move conectan en el espacio y en el tiempo dan como resultado?

Para investigar sobre ello se han seleccionado cuatro ficciones donde se retratan Barcelonas bajo diferentes caracterizaciones (personajes), todas ellas verosímiles, que van de la mano de guiones que han hallado sus historias en dichos escenarios.

PALABRAS CLAVE: Barcelona, cine, escenografía, cartografía.

MARIA ALEJANDRA VILLANOVA es arquitecta y responsable de trabajos practicos en la asignatura Expresión Gráfica de la FAPyD Universidad Nacional de Rosario.

Este texto es una extracto de su tesina, leída en el máster MBArch de la ETSAB línea PPP y dirigida por Pere Fuertes.

\title{
Moderno mundano
}

\author{
Raúl Castellanos Gómez
}

Recibido 2018.05.21 :.: Aceptado 2018.05.28

DOI: 10.5821/palimpsesto.18.5522

a historiografía de la arquitectura moderna ha construido el mito de una modernidad heroica, anunciada en la Europa de los años

de entreguerras, encarnada en la generación de los maestros - que sucederían a los pioneros-, y consagrada prioritariamente al programa de la vivienda social. Pero es sabido que, tras la Segunda Guerra Mundial, tal idea de modernidad quedaría atemperada - los efectos de la contienda contribuirían sin duda a mitigar su mesianismo y su promesa de redención-, al tiempo que, quizá por ello, sus manifestaciones se generalizaban y alcanzaban una difusión, ahora sí, internacional, varias décadas después de ser proclamado el nuevo estilo.

Tras un periodo de aislamiento y autarquía, España accede entonces, paulatinamente, a una modernidad arquitectónica que en lo sucesivo dejará su huella en las nuevas poblaciones y barriadas destinadas a las clases populares, así como en las dotaciones para un incipiente estado del bienestar, e incluso en los edificios públicos más representativos - algunos, de hecho, representarían al país más allá de sus fronterasLa historia aquí reseñada se enmarca en este contexto de apertura. En palabras de su autora, Carla Sentieri, Jaime Roig. Historia de una calle lo es en un triple sentido: en tanto que construcción del pasado; como narración de un suceso; y como registro sistemático de datos. Es ésta una historia de vanguardias y provincias.

El texto nos sitúa a finales de los años cincuenta en una de las zonas de expansión de la ciudad de Valencia compuesta por un tejido residencia burgués, lugar de alojamiento para una clase acomodada de profesionales liberales que abandonan progresivamente el ensanche de la ciudad. Así, uno de los objetivos de la investigación consiste en arrojar luz sobre la evolución desde la vivienda burguesa entre medianeras, característica del ensanche, hacia la edificación abierta que el planeamiento de principios de los cincuenta preveía en el área comprendida entre el Paseo Valencia al Mar y el Camino de Tránsitos. (No en vano sus pares serán el barrio barcelonés de La Bonanova o el romano de Monti Parioli, donde dominaría el tipo residencial de la palazzina).

Jaime Roig es pues la ocasión para una empresa constructiva en la que intervendrán los principales actores de la arquitectura valenciana del momento: Julio Trullenque Sanjuán y Pablo Navarro Alvargonzález; Vicente Valls Abad y Joaquín García Sanz; Cayetano Borso González y Rafael Contel Comenge; Luis Marés Feliu; o el equipo GO.DB. (Fernando Martínez García-Ordóñez y Juan María Dexeus Beatty). Viajes y publicaciones periódicas completarán la formación de estos arquitectos en materia de vivienda burguesa - sus dispositivos espaciales y sus ambigüedades distributivas - , tal y como pusiera de manifiesto la investigación doctoral como pusiera de manifiesto la investigación doctoral Roig, Valencia. De la casa urbana a la vivienda de la ciudad abierta", Universitat Politècnica de València, 2013). Significativa es asimismo la participación del arquitecto madrileño Luis Gutiérrez Soto, cuya trayectoria en el tema de la vivienda burguesa contribuiría a la definición del tipo, caracterizado por la ubicación estratégica de las comunicaciones, la consabida tripartición interior (zona de recepción, zona de familia y zona de servicio), y el protagonismo concedido a la gran terraza ajardinada.

En vano buscaríamos en Jaime Roig un modelo, siendo como es su principal interés la desviación del ideal cuando éste ha de medirse con unas circunstancias concretas, con una realidad urbana Sentieri se detiene en los casos híbridos, impuros - quizá más comprensibles hoy desde una visión desapasionada de la modernidad-: torres que confunden su raíz tipológica y carecen de una estructura general; bloques que comprometen su esbeltez en la conquista de una profundidad que emana del vasto programa doméstico y de la difícil geometría de las parcelas. Dentro de éstas, la orientación de los edificios titubea entre los criterios heliotérmicos y la alineación de las calles, según un planeamiento que se negocia ad hoc y que da lugar a un conjunto azaroso y, no obstante, consistente desde el punto de vista perceptivo y vivencial.

La calle es para Sentieri no sólo un instrumento de planificación sino el lugar de la experiencia. Los espacios libres entre las edificaciones - que hemos aprendido a mirar como la otra forma de la ciudad - se extienden en los generosos zaguanes de las plantas bajas, configurados (incluso amueblados) como si de auténticas viviendas se tratase. Una intimidad traicionada por el paso del tiempo, pues, qué duda cabe de que la sociedad y sus reglas de uso y costumbre han evolucionado de tal manera que, en efecto, uno no puede por menos de sentir hoy cierto pudor ante estas escenas domésticas descontextualizadas. Allí comparece en ocasiones y, por añadidura, el arte en forma de murales y bajorrelieves que, junto al buen hacer de los oficios, configuran una suerte de obra total - uno más de los ideales de aquella primera modernidad, aquí aludidos-

\section{Tratándose de una exposición ordenada de} obras (y sus autores), sometidas a unos mismos criterios de análisis y presentadas mediante una información gráfica exhaustiva y contrastable, el libro de Carla Sentieri adquiere finalmente la forma de un catálogo - la exposición es permanente y puede visitarse a lo largo de la calle Jaime Roig de la ciudad de Valencia-. Pero, ¿acaso deba ser considerado, por encima de todo, un proyecto? Éste permanecería latente tras la lectura del espacio urbano y el análisis de las edificaciones, y, en especial, tras el cuidadoso estudio de sus plantas bajas que diera origen a la investigación - para el arquitecto, la ocasión de volver a proyectar-. Cómo fuera o cómo haya llegado a ser este fragmento de ciudad no serían entonces sino el prólogo de un texto que se omite: cómo podría haber sido.

Valencia: vivienda y ciudad abierta. Jaime Roig. Historia de una calle

Carla Sentieri Omarrementería

Valencia: General de Ediciones de Arquitectura, 2017

ABSTRACT

Con motivo de la publicación del libro de Carla Sentieri, Valencia. Vivienda y ciudad abierta. Jaime Roig. Historia de una calle, este articulo contextualiza sus aportaciones en el marco de la arquitectura española de los años sesenta, y, en especial, de la vivienda burguesa en la ciudad de Valencia. Su evolución desde la construcción entre medianeras característica del ensanche hacia la edificación abierta en los nuevos barrios, los modelos impuros derivados de la torre o el bloque modernos, as ambigüedades distributivas de las viviendas y su tripartición interior, la apertura y la domesticidad de las plantas bajas, son algunos de los temas tratados en el

PALABRAS CLAVE: Calle Jaime Roig, Valencia, arquitectura moderna, vivienda burguesa, edificación abierta, cota cero.

RAÚL CASTELLANOS GÓMEZ es Doctor arquitecto por la UPV, donde es profesor del departamento de Proyectos Arquitectónicos. 